\title{
PERSPECTIVA SOCIOLÓGICA \\ DE LA SEXUALIDAD \\ HACIA EL AÑO 2000
}

Por Licer Viveros C.

En el lenguaje corriente, y también en las definiciones que podemos encontrar en los diccionarios de uso común, la sexualidad se refiere básicamente a las condiciones anatómicas y fisiológicas que caracterizan a cada sexo. Paralelamente, en esta concepción se le adjudica también a la sexualidad una importante significación relacionada con la diferenciación de roles sociales.

Con mayor detalle, desde el punto de vista de la biología, la sexualidad puede ser comprendida a partir de las siguientes características:

- Sexo genético, que se revela por el número de cromosomas existentes en el núcleo de las células o por la substancia albuminosa de gránulos y filamentos que componen la cromatina sexual.

- Sexo hormonal, basado en el equilibrio andrógeno-estrógeno, que contribuye a condicionar el desarrollo de las características masculinas o femeninas.

- Sexo gonádico, referido a la presencia de ovarios o testículos.

- Sexo con referencia a la morfología de los órganos internos de reproducción y,

- Sexo con referencia a los órganos externos de la sexualidad, es decir, los genitales'.

Esta enumeración nos permite, además, el reconocimiento de las llamadas características sexuales secundarias, cuyo desarrollo se completa cuando los individuos superan la etapa de la pubertad. Hay, como puede inferirse, una secuencia específica y coherente de características que nos permiten comprender la sexuali-

Katchadourian. Herant. (Compilador). La sexualidad humana. Fondo de Cultura Económica. México, 1983. Cap. I. 
dad desde el punto de vista biológico y a partir de ellas, emana un importante reconocimiento social en cuanto al rol que cada uno de los individuos de los dos sexos poseen, como capacidad adscrita, en conexión con la reproducción de nuevos integrantes de la especie. Así, el género femenino de la especie puede ser definido como el conjunto de individuos que en el promedio son capaces de concebir y dar a luz. Por su parte, en el género masculino se incluyen aquellos individuos que en el promedio están capacitados para el proceso fisiológico necesario si las potencialidades del otro sexo para la concepción han de llegar a consumarse.

Merece tener presente un pequeño paréntesis a este respecto: los avances de la ingeniería biológica entre otros, por ejemplo, lo que hoy día conocemos como "fertilización in vitro"; de todas maneras, parece inevitable la actividad directa o indirecta de individuos de ambos sexos para la consecución del objetivo final: la reproducción, con lo cual la diferenciación por sexo, al menos hasta ahora, tiende a persistir. Estos hechos nos llevan a sostener que la sexualidad biológica con su multiplicidad de características, constituye un requisito sine qua non para la sobrevivencia y la continuidad de la vida social de la especie humana.

Desde la perspectiva sociológica la sexualidad tiene relevante significación. De hecho ninguna sociedad humana puede ser concebida como un todo monolítico rígidamente moldeado, ni tampoco como una entidad amorfa compuesta por una masa de individuos aislados. En verdad, la sociedad en su expresión más real se manifiesta en la infinita variedad de interacciones y procesos que resultan del sucesivo dar y recibir estímulos, propios de las acciones humanas con sentido social, es decir, con referencias a otros semejantes o equivalentes a nosotros con quienes compartimos una misma cultura. En esta compleja red, o tejido de relaciones, los seres humanos han llegado por diversas razones culturales e históricamente explicables, a reconocer, a partir de la diferenciación sexual, significativas diferenciaciones sociales con referencia, entre otros, al ejercicio del poder, a la asunción de responsabilidades, a la producción y consumo de bienes, a la división del trabajo, a la actividad comercial de compra y venta de bienes de servicios, a los oficios religiosos, etc. Por cierto, aun cuando tales diferenciaciones aparezcan como dependientes de los rasgos biológicos mencionados anteriormente, no podemos sin embargo, establecer de manera categórica que tales diferenciaciones deban aparecer en cualquiera sociedad de cualquier lugar o época. Se sabe de sociedades donde el trabajo pesado está a cargo de las mujeres; donde el poder y la autoridad política ha estado o está en sus manos; donde las oficiantes religiosas han sido sacerdotisas $y$, sin ir más lejos, en nuestros tiempos, la producción y el consumo de vestuario, sea en su forma o en sus colores, aparece casi literalmente indiferenciado (unisex).

De todas maneras, vamos a dejar establecido de manera teórica, con posibilidad de verificación empírica, las siguientes proposiciones: 
1. Siempre ha habido alguna diferenciación de roles teniendo como base la sexualidad.

2. Que esta diferenciación siempre ha estado relacionada con el.factor biofisiológico de la reproducción $y$,

3. Que esta diferenciación no puede ser confinada únicamente a las consideraciones inevitables involucradas en los factores fisiológicos de la reproducción ${ }^{2}$.

A partir de estas proposiciones que pueden servirnos como premisas de carácter muy general, podemos establecer categorizaciones que se refieran, por una parte a la identidad originaria o genérica, en relación con la individualidad de una persona y los rasgos sexuales que persisten, sin importar las circunstancias de lugar, tiempo o situación en que podamos constatarlos. En particular, esta identidad genérica acentúa su importancia durante la etapa de maduración biopsicológica y social que en todos los individuos, con distintos grados de crisis, ocurren durante la adolescencia.

Por otra parte, cabe también distinguir todos los aspectos relacionados con el comportamiento es decir, las modalidades como se exterioriza la sexualidad, sea ésta pública o privada, pues para cada individuo, de acuerdo a su status, hay expectativas y/o prescripciones que orientan su conducta, sea a partir de usos $y$ costumbres o de disposiciones formalizadas legalmente. En este respecto el comportamiento referido a la sexualidad genérica, incluye tres ángulos de expectativas: lo que esperamos de nosotros mismos, lo que otros esperan de nosotros y lo que nosotros esperamos de aquéllos.

Como un efecto ilustrativo de lo que venimos exponiendo, se pueden mencionar las distintas formas de matrimonios que derivan de las relaciones heterosexuales socialmente reconocidas, por ejemplo, la monogamia o la poligamia, en que se considera el número de integrantes de esta relación, y las definiciones culturales para la nupcialidad entre individuos de un mismo grupo o de grupos distintos (endogamia y exogamia). Por último, en este respecto es también muy importante, como se ha verificado en estudios transculturales, el estricto control que se ejerce sobre las llamadas relaciones sexuales incestuosas, cuya evitación se ha conceptualizado con una palabra exótica, de origen polinésico, que significa prohibición, nos referimos al término "tabú" 3 , que no sólo lleva implícito el impedimento, sino también fuertes connotaciones morales vinculadas a sanciones socioculturales graves, con penas o castigos sobrenaturales o divinos. Las escasas excepciones conocidas a esa prohibición aparecen constituyendo prerrogativas especiales de

Levy Marion. The structure of society. Princeton University Press. New Jersey, 1952. Cap. Vil.

Es interesante ver en este respecto lo que se encuentra en: Freud, Sigmund. Obras completas (Vol. II).

Vi Totem y Tabú. Editorial Biblioteca Nueva. Madrid, 1948. 
status o de situaciones especiales, o sea, no están generalizadas en los pueblos distintos $y$ distantes en que se practican. Entre ellos se encuentran: los azande, habitantes del alto Nilo, donde a los nobles se les permitía casarse con sus propias hijas; los aristócratas hawaianos, quienes preferían el matrimonio entre hermano y hermana, hecho que se repite en América del Sur, donde la realeza inca también prefiere tal práctica. Entre los dobuanos de Melanesia la relación heterosexual con la madre no se consideraba muy seria si el padre había muerto. A su vez, los balineses de Indonesia permiten el matrimonio entre mellizos argumentando que ya han estado íntimamente unidos antes de nacer. Por último, los tongas de África consideraban de importancia que antes de una gran cacería se tuvieran relaciones sexuales con la propia hija, acto estimado nefando en otras circunstancias ${ }^{4}$.

Al comienzo de nuestra exposición señalábamos un hecho de singular importancia, la diferenciación biológica del hombre y la mujer; de allí han tenido también su origen las más importantes y significativas diferenciaciones sociales, esto es, la formación de los dos grupos societales más grandes en que pueda dividirse la humanidad: los hombres y las mujeres. En ninguna sociedad se aplica con igual fuerza la normatividad a estos dos grupos. En todas las sociedades hay normas y expectativas diferenciadas de comportamiento para los roles y posiciones de ambos sexos. Ninguna sociedad trata a hombres y mujeres como exactamente iguales. Todavía no se sabe de ninguna sociedad en que realicen actividades idénticas, compartan aspiraciones iguales, o persigan los mismos fines por los mismos caminos. En todas las sociedades hombres y mujeres piensan, hablan, actúan, se visten, realizan diferentes clases de trabajo, en suma sus roles son distintos.

Podría afirmarse, aunque parezca exagerado, que todas las sociedades poseen dos culturas o en último caso tres: la cultura de los hombres, la cultura de las mujeres y la cultura compartida por ambos; de cualquier modo es evidente o verificable que la diferenciación sexual biológica ha desencadenado un sinnúmero de consecuencias sociales; pero, sobre todo, ha permitido enfatizar el hecho de que todas las mujeres comparten dos características fundamentales: La primera radica en el evento biológico de la procreación, de la conservación de la especie, que ensalza a la mujer por el acto de la maternidad, pero que también la esclaviza y limita. A continuación el hecho de que a la mujer, en casi todas las culturas, se le atribuya la condición de segundo sexo. En otras palabras, su mayor privilegio se ha convertido en su mayor limitación.

En el lenguaje figurado y a veces en el lenguaje real, la mujer aparece formando parte del llamado "sexo débil". Sabemos que en términos globales, la mitad de la

4 Murdock. George Peter. Social Structure. The MacMilland Company. New York, 1960, pp. 12-13, 288-289. 
población mundial está compuesta por personas del sexo femenino. Sin embargo, aun cuando las evidencias no son absolutamente concluyentes, las informaciones estadísticas vienen a desmentir la afirmación de su debilidad. Estudios diversos han mostrado que el período de gestación de un niño es entre 5 y 10 días más largos que el de una niña. Al nacer, ellas están mejor desarrolladas que los niños, sus huesos son más fuertes, sus reflejos mejor coordinados, y sus cráneos tienen mejor conformación. La fontanela de las niñas se cierra antes que la de los niños y el desarrollo y fortalecimiento de sus sistemas musculares y óseos es también más rápido. Simultáneamente, ciertas destrezas son adquiridas más rápidamente por las niñas, particularmente aquéllas de tipo manual y lingüístico, o sea, tienen mayor fluidez verbal. Todos sabemos también que la maduración fisiológica de las mujeres supera con largueza a la de los hombres, particularmente cuando nos referimos a las características sexuales primarias y secundarias.

En cuanto a la relación que apunta al dato demográfico de la equitatividad para los dos sexos, no es la misma cuando el análisis se efectúa considerando distintas etapas o ciclos de la vida. Al momento de nacer los varones superan a las mujeres en un $5,5 \%$, o sea, por cada 100 niñas nacen 105,5 hombres. Al año de vida la diferencia es de un $4,5 \%$ esto significa que gran cantidad de niños muere y que el primer año de vida es para el hombre bastante azaroso, ya que es vulnerable a una variedad mayor de patologías que la mujer. En realidad todo es cuestión de diferencias en el número de cromosomas y de glóbulos blancos. Pero hay un hecho curioso, aun la tasa de accidentes es mayor en los niños que en las niñas de esta edad. No se puede, desde luego, argüir que los padres cuidan menos a los niños, simplemente éstos parecen ser más débiles, biológica y culturalmente.

Al llegar a la pubertad los hombres aún superan numéricamente en un $2 \%$ a las mujeres. Cuando se alcanza la madurez las cifras se han igualado y, en las edades posteriores, las mujeres rápidamente superan en número a los hombres. Así a la edad de 60 años las mujeres son $6 \%$ más, a los 75 años $18 \%$ y después de los 90 por cada 100 mujeres hay apenas 50 hombres. Las estadísticas de los organismos internacionales nos informan que las mujeres tienen en el mundo una mayor posibilidad de vida, tanto en las naciones desarrolladas como en las subdesarrolladas, viven en promedio 6 años más que el hombre.

Lo que hasta aquí hemos expuesto nos parece, sin embargo, insuficiente para una cabal comprensión de la expresión comportamiento sexual porque, como bien sabemos, en ella debe incluirse necesariamente un sentido, que aun cuando tenga referentes biológicos, psíquicos o sociales, se carga de una connotación específica que de ninguna manera es accesoria, nos referimos a la sexualidad erótica, es decir, aquélla que se enraiza en el amor sensual, que incluye áreas del organismo eventualmente excitables por su conexión con la sexualidad biopsíquica y que desde Freud han sido denominadas zonas erógenas. 
A su vez este modo de expresarse la sexualidad incluye componentes afectivos y motivacionales, que van desde la simpatía hasta el crimen pasional, pasando por celos, quejas, rabietas, estados angustiosos del ánimo, obsesiones mentales de contenido sexual, fantasias eróticas, etc., que en sus formas más negativas desorganizan la vida interior de las personas al extremo de poder llevarlas a cuadros de neurosis o a alteraciones exageradas como la ninfomanía, el sadismo, el exhibicionismo, etc., para los cuales, como sabemos hay fuertes rechazos y reprimendas morales y sociales.

La sola exposición de los antecedentes que venimos consignando nos lleva a comprender que cuando queremos superar el uso cotidiano informal de la expresión comportamiento sexual, nos encontramos en un ámbito de suyo problemático, por ejemplo, ¿cómo podemos llegar a comprender hechos como la masturbación o el orgasmo nocturno? Al respecto, el conocido investigador norteamericano de la conducta sexual del hombre y la mujer, Alfred Kinsey ${ }^{5}$, definió el comportamiento sexual como aquél que conduce al efecto de orgasmo y redujo la manifestación de la sexualidad erótica a seis formas principales: las caricias, las relaciones heterosexuales, la masturbación, los sueños sexuales, las actividades homosexuales y los contactos con animales.

Cuando citamos investigaciones tan difundidas como las de Kinsey y sus colaboradores, pudiera parecer que la investigación sobre estas materias hubiera disfrutado de muchas facilidades al mismo tiempo que de abundantes refinamientos metodológicos y técnicos. La verdad es que estas afirmaciones sólo han venido a ser efectivas muy recientemente.

Hacia fines del siglo $x \mid x y$ comienzos del $x x$, los movimientos feministas de los inicios se interesaban por responder a la pregunta de si la inteligencia femenina era o no igual a la de los hombres. Durante el segundo cuarto del siglo xx, probablemente bajo la influencia de las teorías psicoanalíticas freudianas, el énfasis recayó en las diferencias de personalidad; florecieron entonces las escalas Masculino-Femenino, esto es, inventarios de la personalidad compuestos de ítems que diferenciaban significativamente a hombres y mujeres. Se amplió así la percepción de comportamiento sexual mucho más allá de lo que corrientemente se entendía por sexual; en otras palabras ya no se establecen categorías sino más bien se particularizan los comportamientos según la motivación sexual en la situación dada. A partir de la década de los años 50 el énfasis se ha referido a las diferencias relativas a! desarrollo, estudiándose los conceptos de rol sexual, pautas de identificación y las relaciones entre variables de personalidad de cada grupo o sexo. De tal manera, el significado de la sexualidad se ha asociado con los ambientes en que se cría y

5 Kinsey Alfred, et al. Sexual Behavior in the human male. W.B. Saunders Co. Filadelfia, 1948, Id. Sexual Behavior in the human female, 1953 
desarrolla un niño, proporcionando rotulaciones sucesivas continuadas a medida que los individuos crecen.

Esto significa, por ejemplo, que una conducta sexual de los 15 años es distinta para las mismas acciones a los 20 y que un asunto erótico es, de todas maneras, emocionalmente distinto si ocurre a los 14 o a los 40 años. Los conceptos recién expuestos nos llevan a tomar nuestra temática refiriéndola a un proceso cuya interpretación es esencialmente sociológica, nos referimos a la socialización es decir, al aprendizaje de las pautas normativas y valóricas existentes en el hogar o en otros sectores de la sociedad. En estos ámbitos se configuran los modelos que facilitan o dificultan las realizaciones esperadas a futuro. Sobre este punto debemos precavernos frente a la pura creencia de que un niño débil y tímido tenga necesariamente que ser afeminado o que una niña admirada por su destreza en los juegos sea necesariamente hombruna. Lo importante en estos niños con estigmas o con habilidades sobresalientes es que no sufrirán alienación alguna en cuanto al desempeño de su rol genérico de sexo si los modelos parentales, de los iguales, de los profesores o de los medios como la televisión, no interfieren en su ajuste al sexo originario y a medida que se desarrollen, su masculinidad o su feminidad llegarán gradualmente a manifestarse en los distintos ciclos vitales, de acuerdo a las expectativas que normalmente se tienen al respecto.

Es un hecho antropológico, social y cultural que la importancia de las caracteristicas biológicas, esencialmente aquéllas que condicionan las destrezas físicas ha do decreciendo y en nuestros tiempos el liderazgo de los grupos, salvo a veces en as manifestaciones deportivas, no está radicado en quienes son o parecen más - jertes. A veces observamos que entre los niños esto todavía tiene vigencia, pero ¿n lo que dice relación con el dominio del entorno, sea éste social o ecológico ya no : ene el vigor físico, la relevancia de tiempos pretéritos. Dos ejemplos sencillos nos ¿ ven para ilustrar este planteamiento. Esa niña fuerte y ahombrada en sus juegos z $\approx$ niños que mencionábamos anteriormente, puede llegar a ser exitosa y atracti- ̇en una sociedad donde la fama de las mujeres atléticas sea altamente recompen$\vdots \vdots$ Ja. A su vez, ese niño débil, rechazado por su timidez puede también alcanzar el $\because$ : 0 siendo un buen estudiante y lograr como culminación los honores académi: :s, mientras sus robustos compañeros de juegos infantiles deambulan sin brillo - a mediocridad de la marginalidad social, de la pobreza y aun de la degradación z ctual.

Hemos expresado anteriormente, que hay distintas formas de manifestarse la $\vdots \vdots$ x alidad en las distintas etapas del desarrollo existencial de una vida humana, : - vién hemos afirmado que el ambiente en que ésta ocurre, actúa como agente - - cionante y naturalmente hemos de aceptar las disparidades que Kinsey ha $-\because$ - do para hombres y mujeres a partir del sistema nervioso central. Debemos $z_{-}=z a r$ además, que si nuestra visión apunta al transcurso del tiempo con sentido - $:-c_{0}$, igualmente constataremos aspectos socioculturales, diversos y cam- 
biantes en cuanto a las respuestas sexuales, a los estímulos eróticos según sea la categoría genérica de los implicados. Se sabe, por ejemplo, que la respuesta a materiales sexo-eróticos impresos o grabados en películas o cintas electromagnéticas provocan una respuesta diferente entre hombres y mujeres, además, esos materiales habitualmente eran preparados para hombres y las mujeres habian aprendido a referirse a ellos de modo negativo. Los estudios más recientes sobre la excitación por la vía visual ya están sugiriendo que la clientela para esos materiales se hace cada vez menos diferenciada y las respuestas asociadas a la sexualidad son comparativamente equivalentes.

Las aseveraciones que venimos formulando nos llevan a postular que, de acuerdo a como se está produciendo la evolución de nuestra cultura, de nuestras normas y de los valores que las orientan harán que, en materias relacionadas con la sexualidad, llegue a haber cada vez una mayor permisividad igualitaria, junto a evaluaciones que no descalifiquen a uno y otro sexo por el modo como sientan, interpreten y exterioricen su respectiva sexualidad. De hecho los estímulos que hasta no hace mucho sólo estaban permitidos para excitar a los hombres, son ahora más accesibles para las mujeres, y todavía más se los define como integrantes deseables de su repertorio de respuestas. Tal vez un aspecto que más que una expectativa para las generaciones que vienen es ya una necesidad, lo constituye una promoción creciente de la educación sexual, no sólo de la biología de la reproducción humana sino de la sexualidad y sus componentes psíquicos, sociales y culturales, que sin degradar al ser humano en estos rasgos de su intimidad, le reduzcan el volumen de tensiones, frustraciones y fracasos resultantes de una sexualidad mal aprendida, mal entendida y erróneamente practicada.

Si desde otra perspectiva sociocultural analizamos la sexualidad en comparación con la satisfacción de otras necesidades básicas del ser humano, estamos en condiciones de proponer que, en el largo proceso del desarrollo cultural algunas actividades cuya finalidad era esencialmente instrumental se fueron convirtiendo, con el dominio de las circunstancias adyacentes, en actividades de las cuales podía derivarse un componente hedonístico, es decir, asociado con la consecución de placer. A modo de ilustración, recordemos dos acciones estrechamente asociadas. En los primeros tiempos, la especie humana practicó la cacería de otros animales con el propósito específico de satisfacer la necesidad básica de alimentarse. Ello implicaba graves riesgos y no pocos hombres perdían la vida en el desigual enfrentamiento con el animal que intentaban matar; posteriormente estas mismas acciones se fueron convirtiendo en acontecimientos sociales que entre otras cosas denotaban el status social de los practicantes: la cetrería, la caza del zorro, la cacería de tórtolas y otras aves tienen un carácter adjetivo en cuanto a la satisfacción de la necesidad básica de alimentarse y son más bien un modo placentero de ocupar los días de ocio en compañía de miembros de la corte o de amigos. 
Del mismo modo, el acto de comer que desde siempre ha estado relacionado con la subsistencia se ha convertido no sólo entre las personas dedicadas a la gastronomía, sino también entre la mayoría de las gentes, cualquiera sea la cantidad o la calidad de los alimentos ingeridos, en una situación privada o social de la que puede derivarse placer.

Llevada la situación a nuestro tema de la sexualidad, mutatis mutandis, podemos proponer afirmaciones similares. Ha habido sociedades en que las relaciones heterosexuales ni siquiera eran asociadas con la reproducción, tal es el caso de los tiwi, un pueblo de unas pequeñas islas del norte de Australia, que casaban a las niñas luego de nacer, en una forma de matrimonio por compromiso con jóvenes prósperos, a fin de evitar los hijos ilegítimos, pues en su cultura se creía que la fecundación se producía de manera no controlable, por espíritus que estaban siempre presentes en la atmósfera local ${ }^{6}$. Es verdad que este es un caso excepcional, pero que nos ayuda en parte a demostrar que la sexualidad no siempre ha estado necesariamente vinculada con la biología de la reproducción y, por lo tanto, nos cabe esperar que si la tecnología médica continúa en sus avances en el manejo de la genética, habremos de llegar a la conclusión que el sexo, más que nunca como antes, se asociará con el placer que los integrantes de una pareja puedan lograr de él y no sería de extrañar que si el síndrome de inmunodeficiencia adquirida (SIDA) no llega a ser controlado y adquiere los riesgos de una pandemia, la sexualidad se manifestará predominantemente de modo heterosexual y en la forma conocida como monogamia.

Aun cuando no es fácil llegar a conclusiones en materias que se caracterizan por su complejidad y más aún por la dificultad de acceso a la información apropiada, nos atrevemos a proponer anticipadamente una conclusión hipotética: la sexualidad que, como hemos visto, incluye relacionadamente los roles genéricos y la conducta sexual es condicionada por factores históricos, sociales y culturales, nos inclinamos entonces a negarle la posibilidad de ser un programa biogenético o evolutivo, para nosotros es, sin lugar a duda, parte de la vida social habitual.

Hasta el momento en nuestra exposición sobre el tema de la sexualidad hemos avanzado analizando, podría decirse, con un cierto optimismo neutral, propio de os manejos científicos de esta problemática, sin considerar casi para nada las evaluaciones socioculturales que desde tiempos inmemorables se han venido formulando para el hecho de ser hombre o mujer. Nadie podría desconocer dos nitos que en este respecto constituyen claves para entender la situación real de los sexos: el primero se refiere a la estigmatización de que ha sido objeto la mujer Jesde que tenemos conocimiento histórico, habiéndosele asignado atributos $y$

Hart C., W.M. and Pilling. Arnold R. The tiwi of north Australia. Holt, Rinehast and Winston. New York, etc. 1961, pp. 14-18. 
calificativos predominantemente negativos que la han llevado a una situación comparativamente desmedrada con respecto al hombre. $Y$ el segundo, como un hecho ya público y notorio, en que constatamos que si bien la situación no ha cambiado, al menos emerge con especial relevancia, sobre todo durante el presente siglo y particularmente, en los últimos tiempos, una fuerte toma de conciencia acerca de aquella situación negativa. Ya no hay dudas hoy día en cuanto al rol cada día más influyente de la mujer en la vida de la sociedad; ellas y también los hombres de ahora, tienen en la cultura occidental puntos de vista diferentes $y$ positivos para evaluar la situación y el rol del sexo femenimo en la sociedad.

Quisiera ilustrar estas afirmaciones haciendo algunos recuerdos acerca de lo que dicen autores y obras que han tenido relevancia e influencia en la historia de nuestra cultura.

En las escrituras bíblicas desde el Génesis (l: 18-23) se habla de la creación de la mujer como complemento necesario del varón adaptada a su esfera y subordinada. Recordemos al respecto que las palabras hebreas que significan hombre y mujer, ish e isha son la misma, siendo la segunda la variante femenina de la primera. En ese contexto el hombre y la mujer aparecen como un solo ser en que las cualidades de uno se complementan con la del otro. Sin embargo, una antigua oración hebrea dice: "alabado sea Dios que no me hizo a mi mujer", que en su versión femenina expresa "alabado sea el Señor que me creó según su deseo". En verdad la visión judeo-cristiana, que tanta influencia ha tenido en la cultura occidental, da a las mujeres un tratamiento ciertamente peyorativo, haciendo de tal condición de sexo un status de por si no deseable.

Las leyendas sobre los orígenes de la especie humana presentan otros matices de la situación. Se dice, por ejemplo, que habiendo Dios creado a Adán observó su producto y notándole ciertas imperfecciones se dijo: "creo que puedo hacerlo mejor" y así creó a Eva. De estos hechos en lo único que parece haber consenso es en cuanto a la creencia que el hombre fue creado primero que la mujer. De tal manera la mujer habiendo sido hecha como un repuesto, es "el segundo sexo de Dios"; como lo dijo el filósofo Nietzsche (1844-1900) "su segunda equivocación". No cabe ahora discutir en términos cualitativos cuál de las dos obras de Dios haya resultado mejor, lo que sí está claro es que existen dos sexos - no uno ni tres-y éste es uno de los hechos indiscutibles en el mundo en que vivimos.

En otro de los textos bíblicos el Apóstol San Pablo dice: "El hombre no es de la mujer, sino ésta de aquél". "El hombre no ha sido creado para la mujer, sino ésta para aquél", "el marido es la cabeza de la mujer, como Cristo es la cabeza de la Iglesia". En la Epístola a los Corintios agrega: "es bueno para el hombre no tocar a la mujer; sin embargo, para evitar el adulterio, que cada hombre tenga su propia mujer y cada mujer su propio marido. Digo por lo tanto a las solteras y viudas es bueno para ellas evitarlo, como yo; pero, si no pueden contenerse, dejarlas que se casen: porque es mejor casarse que quemarse". 
Por su parte, los poetas y filósofos griegos de los tiempos clásicos, que tanto admiramos y a los que con frecuencia nos remitimos cuando queremos matizar nuestros juicios con el toque de su sabiduría, tienen también expresiones para la mujer que pueden considerarse en el mismo nivel de las versiones biblicas.

En la literatura griega del período Homérico (siglo vIII a de C.) la mujer alcanzó talvez el lugar más alto como nunca lo ha tenido. Areté la esposa del Príncipe feacio Alcinoo es honrada por la gente como una divinidad, su sola presencia pone fin a las discusiones, o intercede y aconseja a su marido cuando éste toma decisiones. Cuando Odiseo quiere obtener la ayuda de los feacios para volver a ltaca aconsejado por Nausica, se arrodilla ante la reina, pues sabe que así logrará la ayuda del rey. Cuando Penélope está sola y desvalida, rodeada de pretendientes audaces, sabe que por su condición de mujer sería respetada. Hay, entonces, en este período Homérico una alta educación social de cortesía hacia la mujer que es atendida y honrada porque, en una estirpe orgullosa de caballeros, la mujer puede ser la madre de una descendencia ilustre y es también la mantenedora y guardiana de las más altas costumbres y tradiciones.

Eurípedes (480-406 a. de C.) en su obra Medea, que muestra el aburguesamiento de la vida de su tiempo, le otorga a su protagonista toda su simpatía, principalmente porque considera deplorable el destino de la mujer, donde el resplandor del héroe masculino parecía ser el único digno de alabanza. Es notable en esta obra el fuerte contraste de la lucha entre el amor materno y el ansia de venganza de la esposa burlada. Medea es la heroína de la tragedia matrimonial burguesa, del conflicto entre el egoísmo sin límites del hombre y la pasión infinita de la mujer. Las disputas, las ofensas y el razonamiento que observamos en los personajes son esencialmente burgueses, pues mientras el marido Jason ostenta prudencia y generosidad, Medea reflexiona filosóficamente sobre la posición social de la mujer que llega al matrimonio con un hombre extraño comparado con una rica dote. Es cierto que Medea liberada de las limitaciones de la moral griega, muestra su naturaleza elemental cuando, para ultrajar a su desleal marido, mata bárbaramente a sus hijos, no representa a las mujeres atenienses de su tiempo que eran o muy toscas y oprimidas o demasiado cultivadas. De todas maneras la parricida llega a ser una figura trágica en quien se expresa una fuerte manifestación de rebeldía, junto a una insobornable conciencia crítica en cuanto a su propia condición.

Platón (429-347 a. de C.), cuando agradecía a los Dioses las bendiciones con que supuestamente éstos lo habrían favorecido, declaraba dos motivos fundamentales para expresar sus agradecimientos. Primero el que hubiera nacido libre y no esclavo y segundo el que fuera un hombre y no una mujer. Llama la atención, sin embargo, que en la República nos encontremos con dos ideas notables suyas en relación a la mujer; en una aparece abogando por la comunidad de mujeres como una de las formas que propone para abolir el interés privado. En la otra se manifies- 
ta dispuesto a poner a la mujer en pie de igualdad con el hombre porque, según su opinión, en lo concerniente a ciudadanía no hay diferencias entre la una y el otro.

Aristófanes (445-388 a. de C.), que satirizaba los vicios y las costumbres de su época, mostró en su obra Lisístrata cómo las mujeres de aquellos tiempos reaccionan en defensa de sus hijos y maridos que morían en combate mientras ellas estaban a cargo de la ciudad, diciéndole al Magistrado que las impugnó al mezclarse en asuntos de gobierno: "Señor, la República es para nosotras un fardo muy pesado, mucho más que para ustedes, nosotras cuidamos de nuestros hombres y parimos a nuestros hijos que vosotros mandais a combatir y morir lejos de Atenas". En esta farsa, en que las mujeres llegan al extremo de negarse a cumplir con sus deberes conyugales, ellas son presentadas por Aristófanes para exteriorizar sus sentimientos negativos respecto al valor de la guerra en aras de los sentimientos patrióticos.

Aristóteles (384-322 a. de C.) sostuvo que "la mujer es lo que es en virtud de la carencia de ciertas cualidades" y le atribuyó a ellas "una defectividad natural". En realidad, para los filósofos griegos, la mujer era un mero receptáculo, el principio pasivo; la causa eficiente de un niño era su padre que aporta el principio activo y no su madre, cuya participación es considerada de escaso valor.

Las Leyes Romanas no llegaron tampoco a expresar alguna condescendencia respecto de la mujer, muy por el contrario, limitaron fuertemente sus derechos sobre la base de afirmar "la imbecilidad o inestabilidad del sexo". Es oportuno recordar en lo que respecta a América Latina, donde se ha seguido fuertemente la tradición jurídica romana, la abnegación que se impone a las mujeres casadas de necesitar el consentimiento del marido para la administración de los bienes. Lo mismo podemos decir de Francia hasta el año 1965 y de España hasta la muerte de Franco en 1975, estados donde la mujer era equiparada a la figura del incapaz, que no podía actuar si no era bajo el cuidado o tuición del padre o marido.

El filósofo italiano, máximo representante de la filosofía escolástica del siglo XIII, Santo Tomás de Aquino, dominico y doctor de la Iglesia, afirmó, sin que sepamos de verdad sus razones, que la mujer es "un hombre imperfecto", "un ser incidental".

En la Literatura Clásica Española un ejemplo ilustrativo proviene de nuestras lecturas del teatro de Lope de Vega (1562-1635), quien en su famosa "Fuente Ovejuna" nos presenta la valerosa rebelión de una mujer encarnada en el personaje Laurencia que, de modo inesperado para los tiempos, enfrenta al Comendador del lugar y recibe por la Justicia de sus acciones la aprobación del Rey.

Dando un gran salto en la historia llegamos a una conocida e importante mujer de nuestros tiempos, ella es Simone de Beauvoir quien en su obra "El Segundo Sexo" desarrolla, de comienzo a fin, la tesis de que es degradante ser mujer. Recordemos, entre paréntesis, que Simone de Beauvoir falleció no hace mucho tiempo luego de hacer vida en común con Jean Paul Sartre y digamos además, que 
sus declaraciones poco antes de morir reflejaban con amargura la triste realidad, por una parte de su condición de mujer y por otra, la degradación que experimentó su vida junto al célebre literato existencialistas francés cuando ambos fueron viviendo los años de vejez con todo su cortejo de pequeñas miserias propias de las condiciones de la naturaleza humana deteriorada por la edad.

Decía ella en su obra, en todas las sociedades es la mujer quien ha sido subyugada y esclava, el hombre quien ha sido el amo y rector. La mujer es vasalla, receptáculo, utensilio, mera herramienta del hombre. Ella es conquistada, dominada, vencida tanto en la relación sexual como en la vida. El hombre toma, la mujer da, el hombre actúa, la mujer espera. El óvulo carente de movimiento espera en contraste el espermio libre y ágil tipifica la existencia impaciente y sin descanso. EI hombre es siempre al Uno, la mujer el Otro. El viajero es el Uno cuando está en su hogar, el Otro cuando viaja. La mujer en este sentido, nuncá está en su hogar, siempre está destinada a vagar en el mundo del hombre, nunca en su propio mundo. No hay una dualidad genuina en ambos sexos. La mujer es siempre el Otro ser, nunca el Uno, está condenada a una alienación o alteridad permanente. Así se expresaba Simone de Beauvoir.

Me doy cuenta y comprendo que esta distinguida audiencia ha de estar preguntándose cuáles son las proyecciones hacia el año 2000 que pudieran colegirse a partir de el título de esta modesta conferencia. Quizás de manera sutil sin una intención deliberada y casi sin darnos cuenta, hemos ido esparciendo entre líneas diversas afirmaciones en ese respecto. Podemos esperar que lo biológico en sus rasgos substantivos no experimentará cambios en el breve plazo, excluyendo por cierto las intervenciones quirúrgicas que con finalidad correctiva y de adecuación se efectúan, con no mucha frecuencia pero sí con publicidad, entre aquellos que las necesitan y pueden costearlas. También habremos de reconocer que, aun cuando el modo tradicional de reproducción de la especie humana no se batirá en retirada, ya se sabe de casos en las sociedades de alto desarrollo donde el arriendo de útero permite a la mujer ejecutiva o con muchas exigencias sociales contratar a otra para que en ella se cumpla el proceso que va hasta el nacimiento insertándole el óvulo fecundado por su pareja. Esto que podría violentar nuestras ideas ya está ocurriendo y todavía más, hay constancia de casos llevados a la justicia para establecer quién es realmente la madre, con derechos para adjudicarse la crianza del nuevo ser.

En cuanto al comportamiento social asociado al sexo es posible que el incremento de las concentraciones urbanas, la multiplicación y diversidad de los contactos sociales, al mismo tiempo que el aperturismo a la igualdad de oportunidades, le resten finalmente importancia al sexo genérico para quienes desempeñen los distintos roles sociales. Si algunas diferencias persisten ellas se deberán más a prejuicios culturalmente aceptados que al hecho de ser hombre o mujer. 
En cuanto al sexo erótico, parte de los aspectos biológicos y socioculturales que hemos revisado, podrían tender a liberalizar su comprensión con apoyo en el uso de anticonceptivos no falibles y con un reconocimiento social y cultural que excluya la pecaminosidad y permita por el contrario todos los matices estéticos y hedonistas que no vulneren las normas éticas imperantes en la sociedad.

Como una proposición final, aunque no de carácter conclusivo, podemos establecer que, si bien para la Sociología no es una tarea imposible predecir, en cuanto a las regularidades recurrentes que observaremos hacia el año 2000 con una alta probabilidad de verificación, ellas seguirán manteniendo las características que hasta ahora han presentado. Por una suerte de determinismo proveniente de la biología humana y, en parte talvez más importante, porque la naturaleza misma de la existencia de la sociedad implica la persistencia de rasgos socioculturales, los que en todas las esferas perduran como un modo de conferir y conservar la identidad social del ser humano. 